OPEN ACCESS

Edited by: Lucia Monacis, University of Foggia, Italy

Reviewed by: Annamaria Petito, University of Foggia, Italy

Flavio Ceglie, University of Bari Aldo Moro, Italy

*Correspondence:

Špela Bogataj spela.bogataj@kclj.si

Specialty section: This article was submitted to Movement Science and Sport Psychology, a section of the journal Frontiers in Psychology

Received: 23 June 2020

Accepted: 28 July 2020

Published: 12 August 2020

Citation:

Trajković N, Pajek M, Sporiš G,

Petrinović L and Bogataj Š (2020) Reducing Aggression and Improving Physical Fitness in Adolescents Through an After-School Volleyball Program. Front. Psychol. 11:2081. doi: 10.3389/fpsyg.2020.02081

\section{Reducing Aggression and Improving Physical Fitness in Adolescents Through an After-School Volleyball Program}

\author{
Nebojša Trajković1, Maja Pajek², Goran Sporiš³ ${ }^{3}$ Lidija Petrinović $^{3}$ and Špela Bogataj ${ }^{2,4 *}$ \\ ${ }^{1}$ Faculty of Sport and Physical Education, University of Novi Sad, Novi Sad, Serbia, ${ }^{2}$ Faculty of Sport, University of Ljubljana, \\ Ljubljana, Slovenia, ${ }^{3}$ Faculty of Kinesiology, University of Zagreb, Zagreb, Croatia, ${ }^{4}$ Department of Nephrology, University \\ Medical Centre, Ljubljana, Slovenia
}

This study aimed to determine the effects of an after-school volleyball program on aggression and physical fitness in 14-16 years old students. One hundred and seven participants were randomized to a small-sided volleyball (SSV) training group or a control group (CON). The SSV group completed 8 months of small-sided volleyball training twice a week after school in addition to the regular physical education classes. Yo-Yo Intermittent Recovery Level 1 test (YYIRT1), medicine ball throw (MED), vertical jump $(\mathrm{VJ})$, and Buss and Perry's aggression questionnaire were evaluated before and after 8 months of training. Results revealed a significant interaction effect (group $\times$ time) in total sample for physical aggression $[F(1,105)=17.688 ; p<0.001]$, verbal aggression $[F(1$, $105)=4.973 ; p=0.028]$, anger $[F(1,105)=7.662 ; p=0.007]$, medicine ball throw $[F(1$, $105)=36.143 ; p<0.001]$, and YYIRT1 $[F(1,105)=12.508 ; p=0.001]$. After-school small-sided volleyball for adolescents was accompanied by a significant decrease in aggression compared to physical education classes only. Additionally, adolescents from SSV group showed better results in physical fitness compared to the control group. Our findings significantly contribute to the understanding of possible mechanisms for reducing adolescents' aggression, which include enjoyment, motivation, and self-control through sport intervention.

\section{Keywords: sport, aggression, adolescents, fitness, physiological characteristics, high school}

\section{INTRODUCTION}

Physically active adults have less chronic diseases and lower rates of premature death compared to their inactive counterparts (Bauman, 2004; Physical Activity Guidelines for Americans, 2008). The development of the mentioned conditions is already manifested in childhood and adolescence (Cook et al., 2009; Halfon et al., 2012; Kohl and Cook, 2013). Therefore, the promotion of a healthy and active lifestyle should start in our early life. It is also known that childhood and adolescent physical activity influence on adult morbidity and mortality (Hallal et al., 2006). People create their adulthood lifestyle patterns as they go through adolescence (Hallal et al., 2006). Besides physical inactivity, aggressive behavior is one of the main public health concerns among adolescents (Zinatmotlagh et al., 2013). There are many theories that could explain the occurrence 
of aggressive behavior in children and adolescents. According to Bjorkly (2006), aggressive behavior should be examined through three main groups of aggression theories: psychoanalytic, drive, and learning theory. The most common is the social learning theory (Bandura, 1978) that explains aggressive behavior in children and adolescents by observing other's behavior. One of the most used instruments for measuring aggressive behavior in adolescents has been constructed by Buss and Perry (1992). This model of aggression represents the tendency to respond aggressively when facing rejection, stress, or difficulties (Shachar et al., 2016). The authors grouped the aggression into four factors: physical aggression, verbal aggression, anger, and hostility, combining cognitive, emotional, and behavioral components. Although each factor explained unique variance, this fourfactor structure of the questionnaire sheds light on the specific manifestations of trait aggression (Eastin, 2013).

Innumerable attempts have been made in order to reduce aggression in adolescents (Castillo-Eito et al., 2020). Schoolbased physical activity interventions are practical, effective, and universally applicable (Kriemler et al., 2011; Rodríguez et al., 2016). They were proven to have positive effects on physical fitness and health markers (Dobbins et al., 2013; Sun et al., 2013; Lai et al., 2014). Doubling the frequency of physical education sessions resulted in physical fitness improvement, especially aerobic fitness, which is linked to adolescents' cardiovascular health (Ardoy et al., 2011). One semester of aerobic exercise classes showed significant improvement in cardiorespiratory fitness and a decrease in systolic blood pressure in ninth-grade girls (Ewart et al., 1998). Furthermore, research regarding the psychological benefits of exercise-based school interventions is limited.

Team games (sports) have recently been used to determine the impact on different physical fitness components in the school population (Seabra et al., 2014; Cvetković et al., 2018; Trajković et al., 2020a). Small-sided recreational football has been recognized as one of the most popular and effective team sport in adolescents (Hammami et al., 2018). According to the authors' knowledge, up to date, no study exists that investigated the effects of small-sided games in volleyball on physical fitness in children and adolescents. Moreover, there are only a few studies concerning the impact of sport participation on aggressive behavior in adolescents. Aggression can occur in many forms, from verbal and social aggression to physical assault and violence (Karriker-Jaffe et al., 2008). Typically, aggressive behaviors increase their severity in adolescent development (Loeber and Hay, 1997; Tolan et al., 2000). Therefore, interventions that could decrease aggression in adolescents are highly needed. After-school physical activity (e.g., basketball, football, volleyball, martial arts, capoeira) carried out five times a week, significantly reduced anger, hostile thoughts, physical aggression, and negative emotions in 8-12 years old children (Shachar et al., 2016). The implementation of small-sided recreational football into traditional physical education classes showed to be a beneficial approach for lowering aggression and improving the physical fitness of high-school students (Trajković et al., 2020a). However, some sports of aggressive nature showed the opposite results (Mason and Wilson, 1988;
Monacis et al., 2015). This was confirmed by Kreager (2007), who stated that playing contact sports (e.g., football and wrestling) could subsequently lead to violence. Therefore, it would be interesting to see if sports that have no direct physical contact could transmit their learned behavior on the field into offsport situations.

Additionally, one study showed that participation in sporting activity was associated with an increase in delinquent behavior in adolescents (Begg, 1996). Involvement in competitive sports games increased children's levels of aggression, despite the final result (Nucci and Young-Shim, 2005). Regardless of inconsistent findings, physical activity is still recommended as a method for reducing aggression. One approach that could connect sport participation and aggression is through self-control skills (SCS) (Shachar et al., 2016). The link between sports and SCSs was explained earlier (Marsh and Kleitman, 2003; Miller et al., 2005). The authors mention several mechanisms in sport that could contribute to better SCS. Sports games require attention, focus, and concentration because of the movements and actions that must be performed in a specific order with precise timing as well as because of the compliance with laws and regulations (Marsh and Kleitman, 2003; Miller et al., 2005). Moreover, actions in team sports include mostly the problem-solving situations because while playing, children must make rapid decisions under pressure and think consciously, creatively, and quickly (Marsh and Kleitman, 2003; Miller et al., 2005). Additionally, it was demonstrated that sports activities are positively linked with positive emotions (Chantal et al., 2005; Hyde et al., 2011; Monacis et al., 2014).

In the current study, we expected that changes in enjoyment and positive emotions following school sports intervention would lead to a decrease in the participants' aggressive behavior. The present study aims to determine the effect of after school smallsided volleyball on aggression and physical fitness in 14-16 years old students. It was hypothesized that involvement in smallsided volleyball game would reduce aggression and increase physical fitness.

\section{MATERIALS AND METHODS}

\section{Subjects}

One hundred and seven adolescents from different classes in school were included in the study, of whom $56[n=17$ girls and 38 boys; age $=15.5 \pm 0.7$ years; years to and from peak height velocity (Y-PHV) $=0.4 \pm 0.7$ years] were randomized to a small-sided volleyball training group (SSV) and $51(n=19$ girls and 35 boys; age $=15.7 \pm 0.6$ years; Y-PHV $=0.5 \pm 0.9$ years) to a control group $(\mathrm{CON})$ that maintained their usual physicaleducation activities. There were no time-loss injuries during the volleyball program. The maturity of participants was estimated by predicting age at peak height velocity (PHV) (Malina et al., 2015). All participants were informed verbally and in writing about the procedures and possible risks and agreed to participate in the study with the signed informed consent of their parents or guardians. The study was conducted according to the Declaration of Helsinki, and the ethical approval for the study was obtained 
from the ethics committee of the Faculty of Sport and Physical Education at the University of Novi Sad (Ref. no. 12/2018).

\section{Procedures}

The study was performed in the period from September 2018 to May 2019. Following a series of familiarization sessions, the first week was used for pre-intervention assessment for both the small-sided volleyball group and the control group. In months 18 , the SSV group completed 64 volleyball sessions after school: two scheduled $\sim 45$-min physical-education sessions per week separated by at least 1 day. SSV group had also attended regular physical-education classes. In the same period, the CON group undertook their regular physical-education classes (handball, basketball, gymnastics, table tennis, athletics). Finally, by the end of the 8 months, students from both the SSV and control group completed the same tests as before week 1. In Serbia, it is compulsory for school children to have two 45 min classes of PE per week. Trained university staff members have performed all the necessary tests with a requirement that no physical activity could be performed on the day before the test day 1 .

The test day 1 included body mass and weight, vertical jump, and medicine ball throw, while test day 2 included the Aggression Questionnaire and Yo-Yo intermittent recovery level 1 test (YYIRT1). Before testing, the participants performed a standardized 10-min warm-up consisting of jogging, dynamic stretching, and running drills.

\section{Testing}

Medicine ball throw (Gabbett et al., 2006). The participant held a 2-kg rubber medicine ball (Tigar, Pirot, Serbia) with arms behind head, and throwing the ball over the head straight forward as far as possible. The result is the distance from the front of the line to the point where the ball landed recorded to the nearest $1 \mathrm{~cm}$. Three attempts were made. The best of the three attempts, with a 1 min rest interval between each attempt, was used for further analysis. The intraclass correlation coefficient (ICC) and the coefficient of variation (CV) for measuring medicine ball throw were 0.832 and $3.84 \%$, respectively.

Vertical jump (countermovement jump). We used the Optojump (Optojump photocell system; Microgate, Italy) to measure vertical jump performance. The countermovement jump (CMJ) with arms was chosen as the simplest jump and the most similarities with volleyball jumps. The subjects were instructed to start from the upright position and to perform a CMJ with arm swing during the execution of the jump (i.e., hands were free to move). It was highly recommended for the participants that during their take-off, they leave the floor with the ankles and knees extended and land in a, similarly, extended position. The rest interval between jump repetitions was $30 \mathrm{~s}$. The ICC and CV for vertical jump performance were 0.911 and $2.89 \%$.

Yo-Yo Intermittent Recovery Level 1 test (YYIRT1) was performed according to the guidelines established by Póvoas et al. (2016). YYIRT1 performance and associate measured heart rate (HR) peak are reliable for 9-16 years-old soccer players and non-sports-active boys (Póvoas et al., 2016). Briefly, the participants during YYIRT1 must repeatedly run $2 \times 20$-m back and forth (180-degree turns) between the starting, turning, and the finishing line at a progressively increased speed. The speed was controlled by beeps from an audio device. The test was completed when the participants fail to complete a shuttle within the given signal twice, and the final score is the last shuttle the player has completed. For further analysis, we have used the total distance (meters).

The Aggression Questionnaire was used to assess aggressive behavior (Buss and Perry, 1992). It consists of 29 items that determine four dispositional subtracts of aggression, physical aggression, verbal aggression, anger, and hostility. A five-point Likert scale was used: 5 points (from Extremely uncharacteristic of me $=1$ to Extremely characteristic of me $=5$ ) that can be further aggregated for a general aggression score or calculated separately: The reliability of the instrument in the adolescent population was previously verified (Santisteban and Ma Alvarado, 2009). The internal consistency coefficient (Cronbach's alpha) was 0.88 for physical aggression, 0.89 for verbal Aggression, 0.82 for anger, and 0.84 for hostility.

\section{Training Program}

The small-sided volleyball was played on smaller volleyball courts. A court size (4.5-6 m in width, 9-12 $\mathrm{m}$ in length) was used for playing volleyball 3 vs. 3 and 4 vs. 4 players. Each session consisted of a warm-up lasting $\sim 10 \mathrm{~min}$ [moderateintensity running $(2 \mathrm{~min})$, dynamic stretching $(4 \mathrm{~min})$, and specific volleyball warm up with the ball $(4 \mathrm{~min})], \sim 30 \mathrm{~min}$ of volleyball and $\sim 5$ min of cool-down. The intensity of training was monitored using the Polar Team System H7 (Polar Electro Oy, Kempele, Finland). The same eight players were monitored for the first 2 weeks and the last 2 weeks of the training program. The perceived exertion was measured using the rate of perceived exertion (RPE) scores (10-point scale) collected $30 \mathrm{~min}$ after the end of the sessions during the training period (Foster et al., 2001). Furthermore, we compared the physiological responses and enjoyment between training sessions involving the smallsided volleyball or physical education (PE) classes. A modified Physical Activity Enjoyment Scale (PACES) was completed after the SSV and PE classes (Motl et al., 2001). The PACES consists of a 16-item questionnaire relating, and it uses a 5-point Likert-scale.

The control group undertook their regular PE classes involving ball games (soccer, handball, basketball), instructional training, and individual sports common to many European countries (gymnastics, table tennis, athletics), excluding volleyball. Each type of sports activity lasted around 1 month. In the control group, HR was also monitored during PE classes. Both groups were not engaged in other organized physical activities besides small-sided volleyball and PE classes.

\section{Statistical Analysis}

Data analysis was carried out using SPSS, version 22 (SPSS Inc., Chicago, IL, United States). Mean \pm standard deviation was determined for all outcome measures. The normality of data was checked using the Kolmogorov-Smirnov test and demonstrated that all data had a normal distribution $(p>0.05)$. Moreover, Levene's tests were determined for all psychological outcomes and physical test variables. Test-retest reliability for variables was assessed using the ICC and CV. A two way repeated measures 
ANOVA $(2 \times 2)$ was computed to test for interactions and main effects for time (pre-test vs. post-test) and group (SSV vs. $\mathrm{CON}$ ) on the selected psychological outcomes and physical test variables., The effect size (ES) of each variable was tested using Cohen's $\mathrm{d}$ within each group and was classified as follows: $<0.2$ was defined as trivial; $0.2-0.6$ was defined as small; 0.6-1.2 was defined as moderate; $1.2-2.0$ was defined as large; $>2.0$ was defined as very large, and $>4.0$ was defined as extremely large (Hopkins et al., 2009). Additionally, a partial eta $(\eta)$ squared was used for difference between groups $(0.01=$ small effect, $0.06=$ medium effect, and $0.14=$ large effect) (Pallant, 2007). Statistical significance was set at $p \leq 0.05$.

\section{RESULTS}

For the SSV group, mean HR and RPE during training were $134.6 \pm 12 \mathrm{bpm}$ and $3.2 \pm 0.5 \mathrm{AU}$ (arbitrary unit), respectively. The CON group showed similar results for mean $\mathrm{HR}$ and RPE (137.4 \pm 13bpm; $3.58 \pm 0.6$ AU). Significant differences $(p<0.001)$ were observed for mean PACES between SSV and CON group (Figure 1).

Table 1 presents results from both groups (boys and girls together). Results revealed a significant effect of group (SSV vs. CON) $\mathrm{x}$ time (pre to post) interaction for pagression $[F(1$, $105)=17.688 ; p<0.001]$, vagression $[F(1,105)=4.973$; $p=0.028]$, anger $[F(1,105)=7.662 ; p=0.007]$, medicine ball throw $[F(1,105)=36.143 ; p<0.001]$, and YYIRT1 $[F(1$, $105)=12.508 ; p=0.001]$. Along with the mentioned significance, there was a significant main effect for time in hostility $[F(1$, $105)=22.359 ; p<0.001]$, and $\mathrm{CMJ}[F(1,105)=17.652$; $p<0.001]$.

Results for boys only are presented in Table 2. Pagression $[F(1,71)=12.065 ; p=0.001]$, medicine ball throw $[F(1$, $71)=40.311 ; p<0.001]$, and YYIRT1 $[F(1,71)=12.727$; $p=0.001$ ] demonstrated the significant group (SSV vs. CON $) \times$ time (pre to post) interaction. The significant main effect for time was found for vagression $[F(1,71)=4.650 ; p=0.035]$, hostility $[F(1,71)=11.964 ; p=0.001]$, anger $[F(1,71)=22.690 ; p<0.001]$, and $\mathrm{CMJ}[F(1,71)=11.871 ; p=0.001]$.

Results for girls only are presented in Table 3.

Results for girls indicated a significant group (SSV vs. CON) $\times$ time (pre to post) interaction effect for pagression $[F(1$, $34)=5.437 ; p=0.026]$, vagression $[F(1,34)=4.881 ; p=0.034]$, and anger $[F(1,34)=4.176 ; p=0.049]$. A significant main effect for time was found for hostility $[F(1,34)=10.265$; $p=0.003]$, CMJ $[F(1,34)=5.500 ; p=0.025]$, medicine ball throw $[F(1$, $34)=31.000 ; p<0.001]$, and YYIRT1 $[F(1,34)=21.719$; $p<0.001]$.

\section{DISCUSSION}

Focusing on aggressive behavior in high school children, the current study attempted to demonstrate the effectiveness of after school sports activity intervention for reducing aggressive behavior and improving physical fitness. The major findings were that adolescents from the experimental group after 8 months of after-school volleyball activities, two times per week, reported larger reductions in aggression, in comparison to adolescents from the control group. Additionally, adolescents from small-sided volleyball group showed better results in physical fitness compared to the control group. Moreover, our findings demonstrate that girls showed larger reductions in aggression compared to boys with similar improvements in physical fitness.

Previous after school exercise interventions proved to be a significant factor in reducing aggressive behavior in adolescents (Eccles et al., 2003; Park et al., 2017). There are only a few studies targeting youth psychological outcomes and team sport exercise interventions (Seabra et al., 2014; Shachar et al., 2016; Hammami et al., 2018; Trajković et al., 2020a). However, most of the mentioned studies included recreational football with different formats, with only one intervention that included different sports activities (Shachar et al., 2016). Shachar et al. (2016) found that after-school sports activities (e.g., basketball, soccer, volleyball, martial arts, capoeira) produce larger reductions in anger, hostile thoughts, physical aggression, and negative emotions in comparison to a regular PE classes in children 812 years of age. Concerning adolescents, Trajković et al. (2020a) showed a significant decrease in physical aggression among highschool students participating in the 8-month recreational soccer program compared to $\mathrm{PE}$ classes, which is similar to our results if we look at the total sample. Besides physical aggression, our results showed a significant reduction in verbal aggression and anger. Our results support the fact that those who are engaged in team sports have the potential to promote teamwork, sharing, and better interpersonal relationships with peers and adults, which may significantly contribute to enhancing psychological status (Pedersen and Seidman, 2004). Additionally, compared to other team sports, there is no direct physical contact in volleyball that could lead to the use of physical violence more often (Mutz, 2012). The current study showed that adolescents could transmit their learned behavior on the field into off-sport situations.

Different models were proposed in order to reduce the level of aggression or to improve the management of aggressive behavior. One proven model that was showed to be beneficial in reducing the level of aggression is through indirect mechanisms with the gains in self-control skills in adolescents (Ronen et al., 2007). The research showed that self-control skills were mediating mechanisms that led to reductions in aggressive behavior (Shachar et al., 2016). Moreover, Park et al. (2017) stated that after school sports activities show many psychological advantages by encouraging self-effacement, mutual respect, and consideration. The participants in the current study enrolled in small-sided volleyball showed greater enjoyment compared to participants enrolled in PE classes only (Figure 1), which could be the reason for a greater reduction in aggressive behavior. A recent study stated that the differences between male and female adolescents should be taken into account (Park et al., 2017). Unfortunately, a novel study that included team sport intervention did not show the analysis by gender (Trajković et al., 2020a). Nevertheless, Shachar et al. (2016) showed that physical aggression in girls is changed directly through changes 

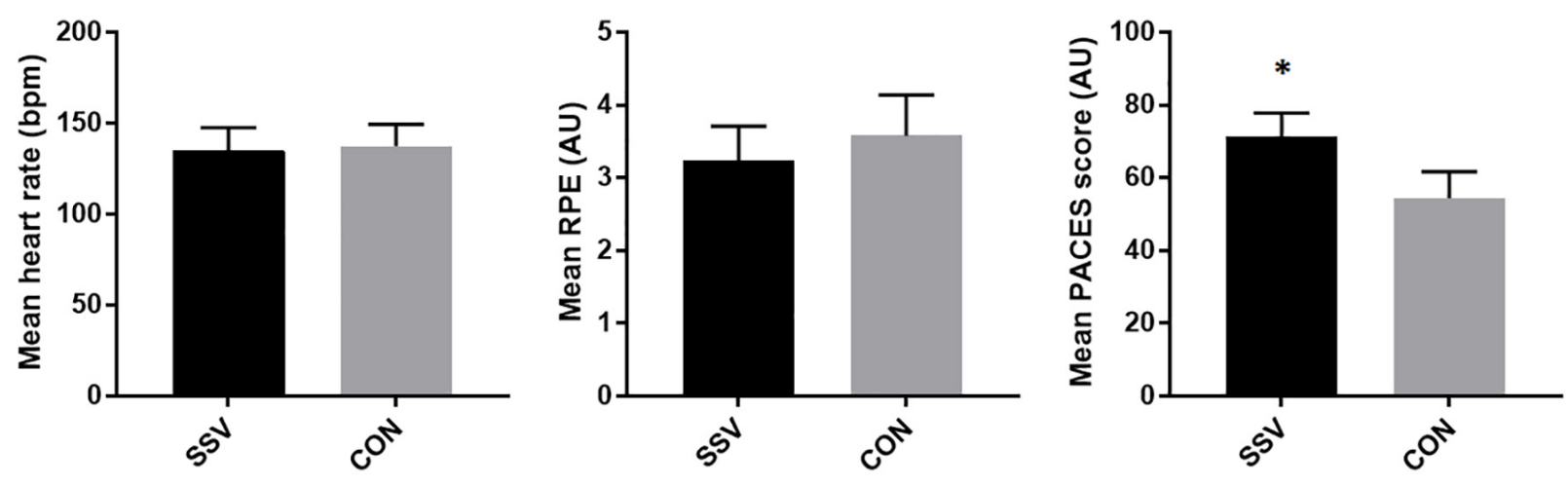

FIGURE 1 | Mean heart rate, mean RPE, and mean PACES score in SSV and CON group during the intervention. RPE, rate of perceived exertion; PACES, Physical Activity Enjoyment Scale; SSV, small-sided volleyball group; CON, control group; *significantly different from the CON group.

TABLE 1 | Changes in physical fitness and aggression measures from pre- to post-test in SSV and CON group for the total sample.

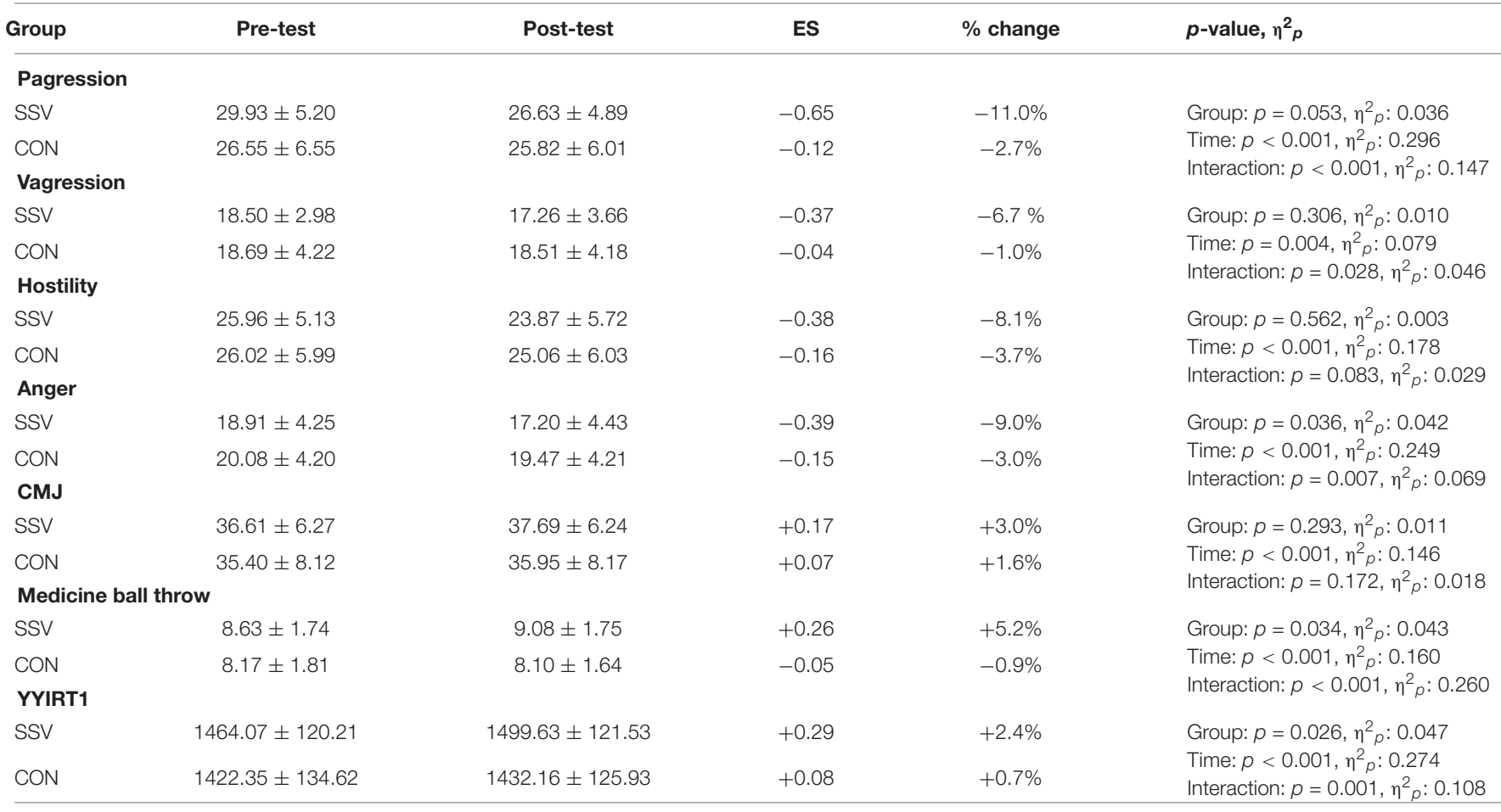

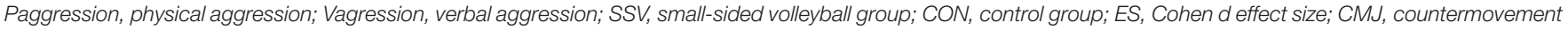
jump; YYIRT1, Yo-Yo intermittent recovery test level 1.

in self-confidence skills. In contrast, changes in self-confidence skills in boys were linked indirectly to changes in physical aggression, through changes in positive and negative emotions. This was confirmed in our study, where boys and girls showed different results for reduction in aggressive behavior. Boys showed an only significant reduction in physical aggression compared to PE classes, while girls significantly reduced physical aggression, verbal aggression, and anger. It was demonstrated that adolescents' aggression decreased over time (Park et al., 2017). Therefore, a possible discrepancy in results between male and female adolescents could be due to the type of intervention, initial status, and slope.
Due to the fact that PE does not provide sufficient opportunities for children and adolescents to achieve the provided recommendations, there has been an increase in the number of after-school physical activity programs (Demetriou et al., 2017). It was demonstrated in previous studies that afterschool exercise programs with fitness emphasis are effective for improving physical fitness in children and adolescents (Ara et al., 2006; Gutin et al., 2008; Carrel et al., 2011). Recreational team sports provide fun and effective options to encourage adolescents to improve their fitness profile (Larsen et al., 2017; Cvetković et al., 2018; Hammami et al., 2018; Trajković et al., 2020a). However, there was only limited positive fitness effects 
TABLE 2 | Changes in physical fitness and aggression measures from pre- to post-test in SSV and CON group for boys.

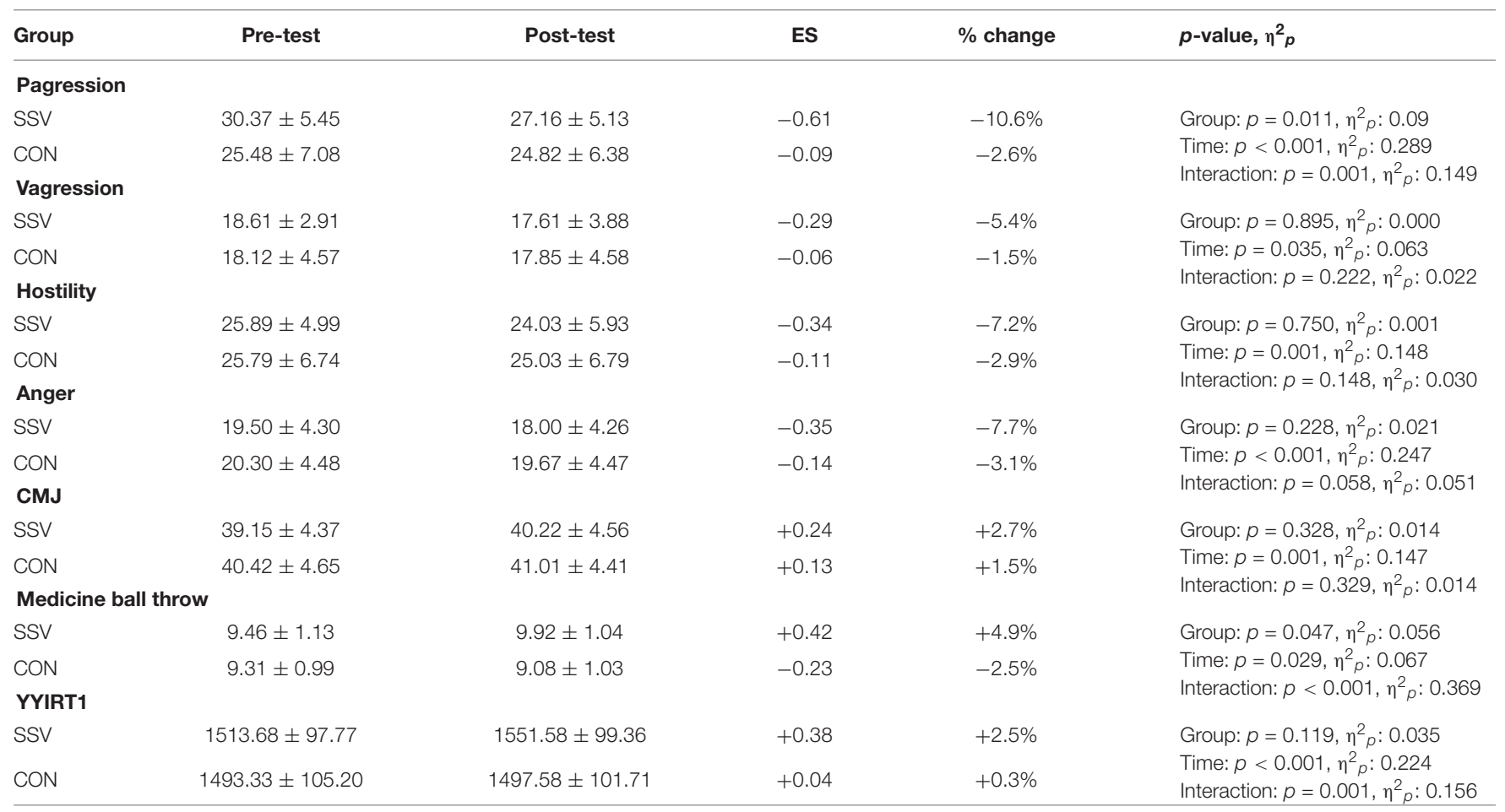

Paggression, physical aggression; Vagression, verbal aggression; SSV, small-sided volleyball group; CON, control group; ES, Cohen d effect size; CMJ, countermovement jump; YYIRT1, Yo-YO intermittent recovery test level 1.

TABLE 3 | Changes in physical fitness and aggression measures from pre- to post-test in SSV and CON group for girls.

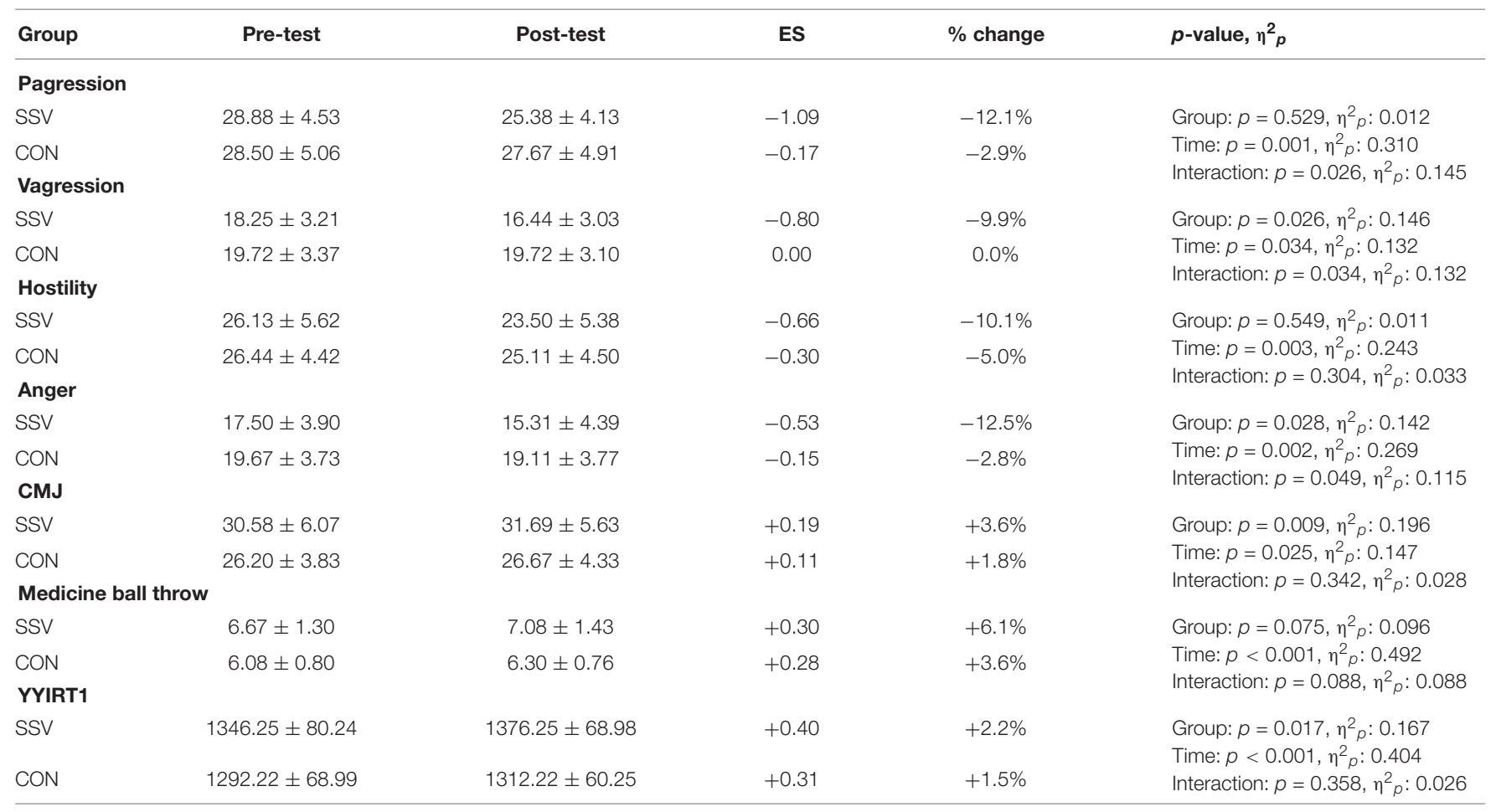

Paggression, physical aggression; Vagression, verbal aggression; SSV, small-sided volleyball group; CON, control group; ES, Cohen d effect size; CMJ, countermovement jump; YYIRT1, Yo-YO intermittent recovery test level 1. 
following frequent low-volume ball games and interval running in children aged 8-10 years (Larsen et al., 2017). On the contrary, greater improvements were found in physical fitness following recreational football intervention in children and adolescents (Cvetković et al., 2018; Hammami et al., 2018; Trajković et al., 2020a).

In the current study, vertical jump (CMJ) was improved by $3.0 \%(\mathrm{ES}=0.17)$ after 8 months of recreational smallsided volleyball training; however, without significant differences between groups. The improvement in vertical jump was expected, having in mind that players in volleyball perform more than 250 jumps in a volleyball match (Martinez, 2017). However, there was a smaller improvement in vertical jump performance in recreational settings, probably due to lower intensity in recreational volleyball (72\% $\mathrm{HR} \max$ and 3.14 RPE) (Trajković et al., 2020b). This was confirmed in a recent study in recreational football training (78-84\% HR max) with significantly greater effects on countermovement jumping (17.0\%; ES $=0.76$, moderate) in overweight and obese children (Cvetković et al., 2018). On the contrary, Hammami et al. (2018) found only limited effects on jump performance in untrained adolescents, following 8 weeks of soccer training. Two studies have used volleyball programs in school students (Sozen, 2012; Selmanović et al., 2013). However, in both studies standing long jump was evaluated after interventions, with contrary results.

The present study found improvement in medicine ball throw in the total sample. Boys showed similar improvements compared to girls following 8 months of small-sided volleyball $(4.9 \%$; $\mathrm{ES}=0.42$ vs. $6.1 \%$; $\mathrm{ES}=0.30)$. In a similar study, Gabbett et al. (2006) found improvements in agility and speed but not in medicine ball throw in adolescent boys following 8 weeks of skill-based training. However, the authors stated that similar pre-training and post-training results for medicine ball throw might be attributed to the low intensity during skill-based training. On the contrary, Gabbett (2008) found greater improvements for medicine ball throw in adolescent boys and girls after skill-based conditioning games, which was due to the higher percentage of time spent at heart rates greater than $85 \%$. The present study had a lower intensity compared to the study of Gabbett (2008), but with a much longer duration of the study (8 months compared to 12 weeks).

There is well-documented evidence that an increase in cardiorespiratory fitness could reduce the risk of developing cardiovascular diseases and premature mortality (Lee and Skerrett, 2001). A major finding in the current study was that cardiorespiratory fitness significantly increased $(2.4 \%)$ with small-sided volleyball, with no significant changes observed in the control group. Our results are similar to those documented in a recent review, which stated that group sports intervention improves cardiorespiratory fitness (pooled ES $=0.53$ ) in overweight and obese children (Oliveira et al., 2017). Our results are also in line with previous studies performed in children and adolescents following recreational soccer programs (Vasconcellos et al., 2016; Hammami et al., 2018; Trajković et al., 2020a). Most of the published studies that involved group sports mainly focus on aerobic activities (e.g., football, basketball, handball) with moderate to high intensity, which is beneficial in improving $\mathrm{VO}_{2}$ peak (Oliveira et al., 2017). Two studies with similar programs were conducted in adolescents already enrolled in volleyball training (Gabbett et al., 2006; Gabbett, 2008). The first study (Gabbett et al., 2006) showed no change in $\mathrm{VO}_{2}$ max following 8 weeks of skill-based training, which was attributed probably to the low average HR (138 beats. $\mathrm{min}^{-1}$ ) achieved during volleyball training. However, the second study (Gabbett, 2008) found greater improvements for $\mathrm{VO}_{2} \max$ in adolescent boys and girls after skill-based conditioning games, which was due to higher intensity.

Some study limitations must be acknowledged. Overall physical activity of the students was not determined before and during the 8-month intervention period. However, they were advised to refrain from participating in any other physical activity during these 8 months. Furthermore, we did not control for dietary intake. However, most of the studies that had only assessed fitness components did not include dietary intake control. Moreover, another limitation is that we did not attempt to contextualize aggression (e.g., passive vs. reactive). However, the major strength of the study is that it was the first to investigate the effects on aggression parameters of schoolbased interventions comprising small-sided volleyball in 15-yearold adolescents. Boys showed better improvements in physical fitness compared to girls. Therefore, future studies should try to modify small-sided games in order to gain higher intensity, which may have a better impact on physical fitness in girls. Additionally, more tests related to health-related fitness should be used to provide a clearer picture of overall health and physical fitness level.

It can be concluded that the after school small-sided volleyball provides an appropriate stimulus for reducing aggression and improving physical fitness in high school students compared with standard PE classes. Girls showed greater reductions in aggressive behavior, while boys had better improvements in physical fitness. In contrast, the control group, which performed only PE classes, showed only small changes over the 8 months intervention. Our findings significantly contribute to the understanding of possible mechanisms for reducing adolescents' aggression, which include enjoyment, motivation, and self-control.

\section{DATA AVAILABILITY STATEMENT}

All datasets generated for this study are included in the article/supplementary material.

\section{ETHICS STATEMENT}

The studies involving human participants were reviewed and approved by the Institutional Ethics Committee from the Faculty of Sport and Physical Education, University of Novi Sad. Written informed consent to participate in this study was provided by the participants' legal guardian/next of kin. 


\section{AUTHOR CONTRIBUTIONS}

NT conceptualized the study design, recruited students into the study, and conducted the research. ŠB analyzed and interpreted the data and drafted the manuscript.

\section{REFERENCES}

Ara, I., Vicente-Rodriguez, G., Perez-Gomez, J., Jimenez-Ramirez, J., SerranoSanchez, J. A., Dorado, C., et al. (2006). Influence of extracurricular sport activities on body composition and physical fitness in boys: a 3-year longitudinal study. Int. J. Obes. 30, 1062-1071. doi: 10.1038/sj.ijo.0803303

Ardoy, D. N., Fernández-Rodríguez, J. M., Ruiz, J. R., Chillón, P., España-Romero, V., Castillo, M. J., et al. (2011). Mejora de la condición física en adolescentes a través de un programa de intervención educativa: estudio EDUFIT. Rev. Esp. Cardiol. 64, 484-491. doi: 10.1016/j.recesp.2011.01.009

Bandura, A. (1978). Social learning theory of aggression. J. Commun. 28, 12-29. doi: 10.1111/j.1460-2466.1978.tb01621.x

Bauman, A. E. (2004). Updating the evidence that physical activity is good for health: an epidemiological review 2000-2003. J. Sci. Med. Sport 7, 6-19. doi: 10.1016/s1440-2440(04)80273-1

Begg, D. (1996). Sport and delinquency: an examination of the deterrence hypothesis in a longitudinal study. Br. J. Sports Med. 30, 335-341. doi: 10.1136/ bjsm.30.4.335

Bjorkly, S. (2006). "Psychological theories of aggression: principles and application to practice," in Violence in Mental Health Settings: Causes, Consequences, Management, eds D. Richter and R. Whittington (New York: Springer), 27-46. doi: 10.1007/978-0-387-33965-8_2

Buss, A. H., and Perry, M. (1992). The aggression questionnaire. J. Pers. Soc. Psychol. 63, 452-459. doi: 10.1037/0022-3514.63.3.452

Carrel, A. L., Logue, J., Deininger, H., Clark, R. R., Curtis, V., Montague, P., et al. (2011). An after-school exercise program improves fitness, and body composition in elementary school children. J. Phys. Educ. Sport Manag. 2, 32-36.

Castillo-Eito, L., Armitage, C. J., Norman, P., Day, M. R., Dogru, O. C., and Rowe, R. (2020). How can adolescent aggression be reduced? A multi-level meta-analysis. Clin. Psychol. Rev. 78:101853. doi: 10.1016/j.cpr.2020.101853

Chantal, Y., Robin, P., Vernat, J. P., and Bernache-Assollant, I. (2005). Motivation, sportspersonship, and athletic aggression: a mediational analysis. Psychol. Sport Exerc. 6, 233-249. doi: 10.1016/j.psychsport.2003.10.010

Cook, S., Auinger, P., and Huang, T. T. K. (2009). Growth curves for cardiometabolic risk factors in children and adolescents. J. Pediatr. 155, S6.e15-S6.e26. doi: 10.1016/j.jpeds.2009.04.051

Cvetković, N., Stojanović, E., Stojiljković, N., Nikolić, D., Scanlan, A. T., and Milanović, Z. (2018). Exercise training in overweight and obese children: recreational football and high-intensity interval training provide similar benefits to physical fitness. Scand. J. Med. Sci. Sport. 28, 18-32. doi: 10.1111/ sms. 13241

Demetriou, Y., Gillison, F., and McKenzie, T. L. (2017). After-school physical activity interventions on child and adolescent physical activity and health: a review of reviews. Adv. Phys. Educ. 07, 191-215. doi: 10.4236/ape.2017.72017

Dobbins, M., Husson, H., Decorby, K., and Larocca, R. L. (2013). Schoolbased physical activity programs for promoting physical activity and fitness in children and adolescents aged 6 to 18. Cochrane Database Syst. Rev. 2013:CD007651.

Eastin, M. (2013). Encyclopedia of Media Violence: One-Volume Set. London: Sage Publications.

Eccles, J. S., Barber, B. L., Stone, M. R., and Hunt, J. E. (2003). Extracurricular activities and adolescent development. J. Soc. Issues 59, 865-889. doi: 10.1046/j. 0022-4537.2003.00095.x

Ewart, C. K., Young, D. R., and Hagberg, J. M. (1998). Effects of school-based aerobic exercise on blood pressure in adolescent girls at risk for hypertension. Am. J. Public Health 88, 949-951. doi: 10.2105/AJPH.88.6.949

Foster, C., Florhaug, J. A., Franklin, J., Gottschall, L., Hrovatin, L. A., Parker, S., et al. (2001). A new approach to monitoring exercise training. J. Strength Cond. Res. 15, 109-115.
MP conducted the research and drafted the manuscript. GS analyzed the data and conducted the research. LP interpreted the data and supervised the research. All authors contributed to the article and approved the submitted version.

Gabbett, T., Georgieff, B., Anderson, S., Cotton, B., Savovic, D., and Nicholson, L. (2006). Changes in skill and physical fitness following training in talentidentified volleyball players. J. Strength Cond. Res. 20, 29-35. doi: 10.1519/R16814.1

Gabbett, T. J. (2008). Do skill-based conditioning games offer a specific training stimulus for junior elite volleyball players? J. Strength Cond. Res. 22, 509-517. doi: 10.1519/JSC.0b013e3181634550

Gutin, B., Yin, Z., Johnson, M., and Barbeau, P. (2008). Preliminary findings of the effect of a 3-year after-school physical activity intervention on fitness and body fat: the medical college of georgia fitkid project. Int. J. Pediatr. Obes. 3, 3-9. doi: 10.1080/17477160801896457

Halfon, N., Verhoef, P. A., and Kuo, A. A. (2012). Childhood antecedents to adult cardiovascular disease. Pediatr. Rev. 33, 51-61. doi: 10.1542/pir.33-2-51

Hallal, P. C., Victora, C. G., Azevedo, M. R., and Wells, J. C. K. (2006). Adolescent physical activity and health: a systematic review. Sport. Med. 36, 1019-1030. doi: 10.2165/00007256-200636120-00003

Hammami, A., Randers, M. B., Kasmi, S., Razgallah, M., Tabka, Z., Chamari, K., et al. (2018). Effects of soccer training on health-related physical fitness measures in male adolescents. J. Sport Heal. Sci. 7, 169-175. doi: 10.1016/j.jshs. 2017.10.009

Hopkins, W. G., Marshall, S. W., Batterham, A. M., and Hanin, J. (2009). Progressive statistics for studies in sports medicine and exercise science. Med. Sci. Sports Exerc. 41, 3-12. doi: 10.1249/MSS.0b013e31818cb278

Hyde, A. L., Conroy, D. E., Pincus, A. L., and Ram, N. (2011). Unpacking the feel-good effect of free-time physical activity: between- and within-person associations with pleasant-activated feeling states. J. Sport Exerc. Psychol. 33, 884-902. doi: 10.1123/jsep.33.6.884

Karriker-Jaffe, K. J., Foshee, V. A., Ennett, S. T., and Suchindran, C. (2008). The development of aggression during adolescence: sex differences in trajectories of physical and social aggression among youth in rural areas. J. Abnorm. Child Psychol. 36, 1227-1236. doi: 10.1007/s10802-008-9245-5

Kohl, H. W. III, and Cook, H. D. (2013). "Physical activity and physical education: relationship to growth, development, and health," in Educating the Student Body: Taking Physical Activity and Physical Education to School, eds H. D. Cook and H. W. Kohl (Washington, DC: National Academies Press).

Kreager, D. A. (2007). Unnecessary roughness? School sports, peer networks, and male adolescent violence. Am. Sociol. Rev. 72, 705-724. doi: 10.1177/ 000312240707200503

Kriemler, S., Meyer, U., Martin, E., Van Sluijs, E. M. F., Andersen, L. B., and Martin, B. W. (2011). Effect of school-based interventions on physical activity and fitness in children and adolescents: a review of reviews and systematic update. Br. J. Sports Med. 45, 923-930. doi: 10.1136/bjsports-2011-090186

Lai, S. K., Costigan, S. A., Morgan, P. J., Lubans, D. R., Stodden, D. F., Salmon, J., et al. (2014). Do school-based interventions focusing on physical activity, fitness, or fundamental movement skill competency produce a sustained impact in these outcomes in children and adolescents? A systematic review of follow-up studies. Sport. Med. 44, 67-79. doi: 10.1007/s40279-013-0099-9

Larsen, M. N., Nielsen, C. M., Ørntoft, C., Randers, M. B., Helge, E. W., Madsen, M., et al. (2017). Fitness effects of 10-month frequent low-volume ball game training or interval running for 8-10-year-old school children. Biomed Res. Int. 2017:2719752. doi: 10.1155/2017/2719752

Lee, I. M., and Skerrett, P. J. (2001). Physical activity and all-cause mortality: what is the dose-response relation?. Med. Sci. Sports Exerc. 33(6 Suppl), S459-471. doi: 10.1097/00005768-200106001-00016

Loeber, R., and Hay, D. (1997). Key issues in the development of aggression and violence from childhood to early adulthood. Annu. Rev. Psychol. 48, 371-410. doi: 10.1146/annurev.psych.48.1.371

Malina, R. M., Rogol, A. D., Cumming, S. P., Coelho, E., Silva, M. J., and Figueiredo, A. J. (2015). Biological maturation of youth athletes: assessment and implications. Br. J. Sports Med. 49, 852-859. doi: 10.1136/bjsports-2015-094623 
Marsh, H. W., and Kleitman, S. (2003). School athletic participation: mostly gain with little pain. J. Sport Exerc. Psychol. 25, 205-228. doi: 10.1123/jsep.25.2.205

Martinez, D. B. (2017). Consideration for power and capacity in volleyball vertical jump performance. Strength Cond. J. 39, 36-48. doi: 10.1519/SSC. 0000000000000297

Mason, G., and Wilson, P. (1988). Sport, Recreation and Juvenile Crime: An Assessment of the Impact of Sport and Recreation Upon Aboriginal and NonAboriginal Youth Offenders. Available online at: https://aic.gov.au/publications/ archive/sport recreation and juvenile crime (accessed June 2, 2020).

Miller, K. E., Melnick, M. J., Barnes, G. M., Farrell, M. P., and Sabo, D. (2005). Untangling the links among athletic involvement, gender, race, and adolescent academic outcomes. Sociol. Sport J. 22, 178-193. doi: 10.1123/ssj.22.2.178

Monacis, L., De Palo, V., and Sinatra, M. (2014). Sportspersonship behaviours: an exploratory investigation of antecedents. Int. J. Sport Psychol. 45, 231-245. doi: 10.7352/IJSP2014.45.231

Monacis, L., De Palo, V., and Sinatra, M. (2015). Motivational factors related to aggression within martial arts context| . Rev. Psicol. del Deport. 24, 163-169.

Motl, R. W., Dishman, R. K., Saunders, R., Dowda, M., Felton, G., and Pate, R. R. (2001). Measuring enjoyment of physical activity in adolescent girls. Am. J. Prev. Med. 21, 110-117. doi: 10.1016/S0749-3797(01)00326-9

Mutz, M. (2012). Athletic participation and the approval and use of violence: a comparison of adolescent males in different sports disciplines. Eur. J. Sport Soc. 9, 177-201. doi: 10.1080/16138171.2012.11687896

Nucci, C., and Young-Shim, K. (2005). Improving socialization through sport: an analytic review of literature on aggression and sportsmanship. Phys. Educ. 62, 123-129.

Oliveira, A., Monteiro, Â, Jácome, C., Afreixo, V., and Marques, A. (2017). Effects of group sports on health-related physical fitness of overweight youth: a systematic review and meta-analysis. Scand. J. Med. Sci. Sport 27, 604-611. doi: $10.1111 /$ sms. 12784

Pallant, J. (2007). A Step by Step Guide to Data Analysis Using SPSS for Windows, 3rd Edn. New York, NY: McGraw Hill Open University Press.

Park, S., Chiu, W., and Won, D. (2017). Effects of physical education, extracurricular sports activities, and leisure satisfaction on adolescent aggressive behavior: a latent growth modeling approach. PLoS One 12:e0174674. doi: 10.1371/journal.pone.0174674

Pedersen, S., and Seidman, E. (2004). Team sports achievement and self-esteem development among urban adolescent girls. Psychol. Women Q. 28, 412-422. doi: 10.1111/j.1471-6402.2004.00158.x

Physical Activity Guidelines for Americans (2008). Available online at: www.health.gov/paguidelines (accessed June 1, 2020). doi: 10.1111/j.14716402.2004.00158.x

Póvoas, S. C. A., Castagna, C., Soares, J. M. C., Silva, P. M. R., Lopes, M. V. M. F., and Krustrup, P. (2016). Reliability and validity of Yo-Yo tests in 9- to 16-yearold football players and matched non-sports active schoolboys. Eur. J. Sport Sci. 16, 755-763. doi: 10.1080/17461391.2015.1119197

Rodríguez, A., María, Esquivel, J., Rodríguez, H., Fonseca, H., José, M., et al. (2016). Effect of a program of sport-recreational activities on aggression and prosocial values among youth living in social risk. Eur. J. Hum. Mov. 37, $143-162$.

Ronen, T., Rahav, G., and Moldawsky, A. (2007). Aggressive behavior among Israeli elementary school students and associated emotional/behavioral problems and self-control. Sch. Psychol. Q. 22, 407-431. doi: 10.1037/1045-3830.22.3.407
Santisteban, C., and Ma Alvarado, J. (2009). The aggression questionnaire for spanish preadolescents and adolescents: AQ-PA. Span. J. Psychol. 12, 320-326. doi: $10.1017 /$ S1138741600001712

Seabra, A. C., Seabra, A. F., Brito, J., Krustrup, P., Hansen, P. R., Mota, J., et al. (2014). Effects of a 5-month football program on perceived psychological status and body composition of overweight boys. Scand. J. Med. Sci. Sport. 24, 10-16. doi: $10.1111 /$ sms. 12268

Selmanović, A., Milanović, D., and Èustonja, Z. (2013). Effects of an additional basketball and volleyball program on motor abilities of fifth grade elementary school students. Coll. Antropol. 37, 391-400.

Shachar, K., Ronen-Rosenbaum, T., Rosenbaum, M., Orkibi, H., and Hamama, L. (2016). Reducing child aggression through sports intervention: the role of selfcontrol skills and emotions. Child. Youth Serv. Rev. 71, 241-249. doi: 10.1016/j. childyouth.2016.11.012

Sozen, H. (2012). The effect of volleyball training on the physical fitness of high school students. Proc. Soc. Behav. Sci. 46, 1455-1460. doi: 10.1016/j.sbspro. 2012. 05.320

Sun, C., Pezic, A., Tikellis, G., Ponsonby, A.-L., Wake, M., Carlin, J. B., et al. (2013). Effects of school-based interventions for direct delivery of physical activity on fitness and cardiometabolic markers in children and adolescents: a systematic review of randomized controlled trials. Obes. Rev. 14, 818-838. doi: 10.1111/obr.12047

Tolan, P. H., Gorman-Smith, D., and Loeber, R. (2000). Developmental timing of onsets of disruptive behaviors and later delinquency of inner-city youth. J. Child Fam. Stud. 9, 203-220. doi: 10.1023/A:1009471021975

Trajković, N., Madić, D., Milanović, Z., Maèak, D., Padulo, J., Krustrup, P., et al. (2020a). Eight months of school-based soccer improves physical fitness and reduces aggression in high-school children. Biol. Sport 37, 185-193. doi: 10. 5114/biolsport.2020.94240

Trajković, N., Sporiš, G., Kristièević, T., and Bogataj, Š (2020b). Effects of small-sided recreational volleyball on health markers and physical fitness in middle-aged men. Int. J. Environ. Res. Public Health 17:3021. doi: 10.3390/ ijerph 17093021

Vasconcellos, F., Seabra, A., Cunha, F., Montenegro, R., Penha, J., Bouskela, E., et al. (2016). Health markers in obese adolescents improved by a 12 -week recreational soccer program: a randomised controlled trial. J. Sports Sci. 34, 564-575. doi: 10.1080/02640414.2015.1064150

Zinatmotlagh, F., Ataee, M., Jalilian, F., Mirzaeialavijeh, M., Aghaei, A., and Karimzadeh Shirazi, K. (2013). Predicting aggression among male adolescents: an application of the theory of planned behavior. Heal. Promot. Perspect. 3, 269-26975. doi: 10.5681/hpp.2013.031

Conflict of Interest: The authors declare that the research was conducted in the absence of any commercial or financial relationships that could be construed as a potential conflict of interest.

Copyright (C) 2020 Trajković, Pajek, Sporiš, Petrinović and Bogataj. This is an openaccess article distributed under the terms of the Creative Commons Attribution License (CC BY). The use, distribution or reproduction in other forums is permitted, provided the original author(s) and the copyright owner(s) are credited and that the original publication in this journal is cited, in accordance with accepted academic practice. No use, distribution or reproduction is permitted which does not comply with these terms. 